ORIGINAL ARTICLE

\section{Timing of Initiation of Antiretroviral Drugs during Tuberculosis Therapy}

\author{
Salim S. Abdool Karim, M.B., Ch.B., Ph.D., Kogieleum Naidoo, M.B., Ch.B., \\ Anneke Grobler, M.Sc., Nesri Padayatchi, M.B., Ch.B., Cheryl Baxter, M.Sc., \\ Andrew Gray, M.Sc. (Pharm.), Tanuja Gengiah, M.Clin.Pharm., M.S. (Epi.), \\ Gonasagrie Nair, M.B., Ch.B., Sheila Bamber, M.B., Ch.B., Aarthi Singh, M.B., Ch.B., \\ Munira Khan, M.B., Ch.B., Jacqueline Pienaar, M.Sc., Wafaa El-Sadr, M.D., M.P.H., \\ Gerald Friedland, M.D., and Quarraisha Abdool Karim, Ph.D.
}

\section{ABSTRACT}

\section{BACKGROUND}

The rates of death are high among patients with coinfection with tuberculosis and the human immunodeficiency virus (HIV). The optimal timing for the initiation of antiretroviral therapy in relation to tuberculosis therapy remains controversial.

\section{METHODS}

In an open-label, randomized, controlled trial in Durban, South Africa, we assigned 642 patients with both tuberculosis and HIV infection to start antiretroviral therapy either during tuberculosis therapy (in two integrated-therapy groups) or after the completion of such treatment (in one sequential-therapy group). The diagnosis of tuberculosis was based on a positive sputum smear for acid-fast bacilli. Only patients with HIV infection and a CD4+ cell count of less than 500 per cubic millimeter were included. All patients received standard tuberculosis therapy, prophylaxis with trimethoprim-sulfamethoxazole, and a once-daily antiretroviral regimen of didanosine, lamivudine, and efavirenz. The primary end point was death from any cause.

\section{RESULTS}

This analysis compares data from the sequential-therapy group and the combined integrated-therapy groups up to September 1, 2008, when the data and safety monitoring committee recommended that all patients receive integrated antiretroviral therapy. There was a reduction in the rate of death among the 429 patients in the combined integrated-therapy groups (5.4 deaths per 100 person-years, or 25 deaths), as compared with the 213 patients in the sequential-therapy group (12.1 per 100 person-years, or 27 deaths); a relative reduction of $56 \%$ (hazard ratio in the combined integrated-therapy groups, $0.44 ; 95 \%$ confidence interval, 0.25 to 0.79 ; $\mathrm{P}=0.003)$. Mortality was lower in the combined integrated-therapy groups in all CD4+ count strata. Rates of adverse events during follow-up were similar in the two study groups.

\section{CONCLUSIONS}

The initiation of antiretroviral therapy during tuberculosis therapy significantly improved survival and provides further impetus for the integration of tuberculosis and HIV services. (ClinicalTrials.gov number, NCT00398996.)
From the Centre for the AIDS Programme of Research in South Africa (CAPRISA), University of KwaZulu-Natal, Durban, South Africa (S.S.A.K., K.N., A.G., N.P., C.B., A.G., T.G., G.N., S.B., A.S., M.K., J.P., Q.A.K.); the Department of Epidemiology (S.S.A.K., W.E.-S., Q.A.K.) and the International Center for AIDS Care and Treatment Programs (ICAP) (W.E.-S.), Mailman School of Public Health, Columbia University, New York; and the Department of Internal Medicine and Epidemiology, Yale University School of Medicine, New Haven, CT (G.F.). Address reprint requests to Dr. S. Abdool Karim at CAPRISA, Doris Duke Medical Research Institute, 2nd Fl., Nelson R. Mandela School of Medicine, University of KwaZulu-Natal, Private Bag X7, Congella, 4013 Durban, South Africa, or at caprisa@ukzn.ac.za.

N EngIJ Med 2010;362:697-706.

Copyright (C) 2010 Massachusetts Medical Society. 
I $\mathrm{N}$ 2007, IT WAS ESTIMATED THAT THERE were about 33 million persons living with human immunodeficiency virus (HIV) infection ${ }^{1}$ and 9.2 million persons with newly diagnosed tuberculosis worldwide. ${ }^{2}$ The two diseases are closely intertwined, and the number of patients with coinfection continues to grow rapidly. ${ }^{3} \mathrm{Tu}-$ berculosis is the most common opportunistic disease $^{4}$ and the most common cause of death in patients with HIV infection in developing countries. $^{5}$ Notwithstanding effective tuberculosis chemotherapy, in the presence of HIV infection, tuberculosis is associated with substantially increased case fatality rates ${ }^{6}$ and is also the most commonly reported cause of death in South Africa. ${ }^{7}$ In 2007 in South Africa, an estimated 5.3 million people were infected with HIV and 341,165 with tuberculosis, of whom approximately $73 \%$ were coinfected with HIV. ${ }^{8}$

The optimal timing for the initiation of antiretroviral therapy in patients with HIV and tuberculosis coinfection remains unclear. Current guidelines are based on observational studies and expert opinion. ${ }^{9}$ Despite World Health Organization (WHO) guidelines supporting concomitant treatment of the two diseases and urging more aggressive management, ${ }^{10}$ the initiation of antiretroviral therapy is often deferred until completion of tuberculosis therapy because of concern about potential drug interactions between rifampin and some classes of antiretroviral drugs, ${ }^{11}$ the immune reconstitution inflammatory syndrome, ${ }^{12,13}$ overlapping side effects, ${ }^{14}$ a high pill burden, and programmatic challenges. ${ }^{15}$ This study, called the Starting Antiretroviral Therapy at Three Points in Tuberculosis (SAPIT) trial, was designed to determine the optimal time to initiate antiretroviral therapy in patients with HIV and tuberculosis coinfection who were receiving tuberculosis therapy.

\section{METHODS}

\section{STUDY DESIGN}

The study was an open-label, randomized, controlled trial conducted at the eThekwini HIVtuberculosis clinic, which is operated by the Centre for the AIDS Programme of Research in South Africa (CAPRISA) in Durban, South Africa. This clinic adjoins one of the largest outpatient tuberculosis facilities in South Africa, the Prince Cyril Zulu Communicable Disease Centre.

Guidelines of the South African National Tu- berculosis Control Programme ${ }^{16}$ stipulate that a first episode of tuberculosis be treated with a 2-month intensive combination-drug regimen of rifampin, isoniazid, ethambutol, and pyrazinamide, with doses determined according to pretreatment weight. Thereafter, patients receive a 4-month continuation regimen of isoniazid and rifampin. Patients with a history of tuberculosis receive a 3-month intensive regimen (including the addition of streptomycin for the first 2 months), followed by a 5-month continuation phase. In our study, patients were routinely offered therapy that was directly observed by clinic-based nurses. Some patients selected community-based supervisors, heads of households, and treatment supporters in workplaces who supervised and recorded the taking of medication.

\section{PATIENTS}

From June 28, 2005, to July 11, 2008, we recruited patients who were at least 18 years of age and who had confirmed HIV infection (on the basis of two rapid HIV tests) and a positive smear for tuberculosis acid-fast bacilli (with the use of auramine and Ziehl-Neelsen staining methods). Inclusion in the study required independent confirmation of positive tuberculosis status at the Department of Medical Microbiology at the Nelson R. Mandela School of Medicine, initiation of treatment with the standard tuberculosis regimen at the Communicable Disease Centre, a CD4+ cell count of less than 500 per cubic millimeter at screening, and an absence of clinical contraindications to the initiation of antiretroviral therapy. Female patients were required to agree to use contraception while receiving efavirenz.

\section{STUDY PROCEDURES}

After providing written informed consent, patients with confirmed HIV and tuberculosis coinfection were randomly assigned in a 1:1:1 ratio (with the use of sealed envelopes) to one of three study groups in permuted blocks of six or nine with no stratification. In the first group, antiretroviral therapy was to be initiated within 4 weeks after the start of tuberculosis therapy (early integratedtherapy group). In the second group, antiretroviral therapy was to be initiated within 4 weeks after the completion of the intensive phase of tuberculosis therapy (late integrated-therapy group). In the third group, antiretroviral therapy was to be initiated within 4 weeks after the completion of tuberculosis therapy (sequential-therapy group). 
All patients received adherence counseling, prophylaxis with trimethoprim-sulfamethoxazole against HIV-related opportunistic infections, and the same once-daily three-drug antiretroviral therapy regimen, consisting of didanosine ( $250 \mathrm{mg}$ for a body weight of $<60 \mathrm{~kg}$ and $400 \mathrm{mg}$ for a weight $\geq 60 \mathrm{~kg}$ ), lamivudine ( $300 \mathrm{mg}$ ), and efavirenz (600 mg). Adherence to the antiretroviral regimen was assessed monthly according to pill counts (pills issued minus pills returned as a percentage of anticipated pill consumption). Regardless of the study-group assignment, patients could be started on antiretroviral therapy at any time by clinicians at the Communicable Disease Centre, by study clinicians, or by personal physicians at their discretion.

Follow-up visits for the monitoring of safety and clinical status were scheduled monthly for 24 months. Adverse events were graded with the use of the Division of AIDS Table for Grading the Severity of Adult and Pediatric Adverse Events, version 1.0, as recommended by the National Institute of Allergy and Infectious Diseases (December 28, 2004). Measurements of CD4+ cell counts with the use of flow cytometry (FACSCalibur, Becton Dickinson) and HIV RNA (Cobas Amplicor HIV-1 Monitor, version 1.5, Roche) were performed at the time of screening, at randomization, and every 6 months thereafter. Monitoring for radiologic changes and sputum conversion was performed at the time of screening, at the end of the intensive phase of tuberculosis therapy, 1 month before the end of tuberculosis therapy, and whenever clinically indicated.

\section{END POINTS}

The primary end point was death from any cause. Secondary end points included discontinuation because of side effects, toxic effects, HIV RNA levels, tuberculosis outcomes, and the occurrence of the immune reconstitution inflammatory syndrome. Discontinuation because of side effects was documented as study-initiated treatment interruptions in the pharmacy records. Toxic effects were assessed by means of a clinical checklist and standard laboratory tests for hematologic, hepatic, and renal abnormalities. The immune reconstitution inflammatory syndrome was defined as a paradoxical deterioration in clinical status or laboratory findings after the initiation of antiretroviral or antituberculosis therapy without another attributable cause.

\section{INTERIM MONITORINC}

After a planned interim analysis, on September 1, 2008, almost 2 months after completion of enrollment, the data and safety monitoring committee recommended that all patients in the sequential-therapy group be started on antiretroviral therapy as soon as possible but continue in follow-up until study completion. The committee also recommended continuation of the two integrated-therapy groups with no changes. The patients in the sequential-therapy group were contacted within a week after the committee's meeting, and almost all of them started antiretroviral therapy within a month. We present data up to September 1, 2008, comparing the sequential-therapy group with the combined early and late integrated-therapy groups, which are hereafter referred to as the integrated-therapy group.

\section{STUDY OVERSIGHT}

The trial was approved by the Biomedical Research Ethics Committee at the University of KwaZuluNatal and the South African government's Medicines Control Council.

\section{STATISTICAL ANALYSIS}

We estimated that we would need to enroll 649 patients (factoring in an anticipated loss to follow-up) in order to have a power of $80 \%$ and an alpha level of 0.05 to detect a $60 \%$ reduction in mortality on the basis of a predicted death rate of $10 \%$ in the study group with the worst outcome. All analyses were performed according to the intention-to-treat principle. The primary outcome was analyzed with the use of Kaplan-Meier curves and the log-rank test. The duration of time in the study was calculated as the time from randomization to death, withdrawal from the study, or the cutoff date of September 1, 2008, whichever occurred first. Poisson approximations were used to calculate confidence intervals for the rate of death. Proportional-hazards regression models were used to adjust for confounding variables. Fisher's exact test was used for the analysis of categorical data, and unpaired t-tests or the Wilcoxon two-sample test for the analysis of continuous data.

\section{RESULTS}

\section{PATIENTS}

A total of 642 patients with HIV and tuberculosis coinfection were enrolled: 429 in the combined 
integrated-therapy group and 213 in the sequential-therapy group (Fig. 1). At baseline, patients in the two groups had similar demographic and clinical characteristics, including age, CD4+ cell counts, and HIV RNA levels (Table 1).

\section{FOLLOW-UP}

At the time of the data cutoff, on September 1, 2008 , a total of 338 of the 642 patients $(52.6 \%)$ were still in active follow-up, 52 (8.1\%) had died during follow-up, 134 (20.9\%) had completed follow-up, and 56 (8.7\%) had withdrawn before study completion. Of the 62 patients $(9.7 \%)$ who were regarded as lost to follow-up $(9.6 \%$ in the integrated-therapy group and $9.9 \%$ in the sequential-therapy group), 35 were known to be alive, and the clinical status of the remaining 27 was unknown. (Patients were considered to be lost to follow-up if they went 4 months without a visit.) The median duration of follow-up in the trial was 12.1 months (interquartile range, 6.1 to 21.6).

\section{INITIATION OF ANTIRETROVIRAL THERAPY}

The median duration of tuberculosis therapy was similar among patients who completed such therapy: 210 days for 271 patients in the integratedtherapy group and 207 days for 137 patients in the sequential-therapy group. At the time of this analysis, 102 patients in the integrated-therapy group and 48 patients in the sequential-therapy group were still receiving tuberculosis therapy.

Of the 350 patients in the integrated-therapy group who started antiretroviral therapy, $338 \mathrm{did}$ so while they were receiving tuberculosis therapy. Patients in this group started antiretroviral therapy at a mean $( \pm S D)$ of $70 \pm 72$ days after the start of tuberculosis therapy. Of the 100 patients in the sequential-therapy group who started antiretroviral therapy, 7 did so while they were receiving tuberculosis therapy. In this group, antiretroviral therapy was initiated a mean of $260 \pm 71$ days after the initiation of tuberculosis therapy. Thus, patients in the sequential-therapy group started antiretroviral therapy, on average, 190 days later than those in the integrated-therapy group.

\section{PRIMARY END POINT}

There were 25 deaths in the integrated-therapy group, for a death rate of 5.4 per 100 person-years, as compared with 27 deaths in the sequentialtherapy group, for a death rate of 12.1 per 100 person-years (hazard ratio in the integrated-therapy group, $0.44 ;$ 95\% confidence interval [CI], 0.25 to $0.79 ; \mathrm{P}=0.003$ ) (Table 2 and Fig. 2). After adjustment for baseline WHO status of HIV infection (stage 4 vs. stage 3), CD4+ cell count, age, sex, the presence or absence of a history of tuberculosis, the presence or absence of extrapulmonary tuberculosis, and baseline HIV RNA level, the hazard ratio was 0.43 (95\% CI, 0.25 to $0.77 ; \mathrm{P}=0.004$ ).

Information on the 52 deaths was based on hospital chart notes for 28 patients, a death certificate for 1 patient, and two independent oral reports of death for 23 patients. On the basis of the chart notes and death certificate for $29 \mathrm{pa}-$ tients, causes of death in the integrated-therapy group were tuberculosis (including tuberculous meningitis) for 2 patients, respiratory distress or Pneumocystisjiroveci pneumonia for 6 patients, and metabolic acidosis, cardiomyopathy, and a motorvehicle accident for 1 patient each; causes of death in the sequential-therapy group were tuberculosis (including tuberculous meningitis) for 6 patients, respiratory distress or P. jiroveci pneumonia for 3 patients, and nontuberculous meningitis, gastroenteritis, renal failure, hepatic failure, and glioma for 1 patient each. The cause of death was unclear in the chart notes of four patients.

The baseline CD4+ cell count independently predicted mortality in the two study groups. Mortality was lower in the integrated-therapy group in all CD4+ count strata (Table 2). The median baseline CD4+ count was similar in the two study groups. There was no interaction between the $\mathrm{CD} 4+$ count and the study groups $(\mathrm{P}=0.57)$.

\section{TREATMENT OUTCOMES}

The rate of adherence to antiretroviral therapy according to pill counts was $97.2 \%$ in the integrated-therapy group and $97.6 \%$ in the sequentialtherapy group. Outcomes with respect to tuberculosis therapy were similar in the two study groups, regardless of whether patients were receiving first-episode therapy or repeated therapy (Table 3). At 12 months after randomization, the proportion of patients with a suppressed HIV RNA level was higher in the integrated-therapy group than in the sequential-therapy group $(90.0 \%$ vs. $77.8 \%, \mathrm{P}=0.006$ ). However, the proportion of patients with a suppressed HIV RNA level 6 months after the initiation of antiretroviral therapy was similar in the two groups (Table 4).

\section{ADVERSE EVENTS}

The immune reconstitution inflammatory syndrome was diagnosed in 53 of 429 patients (12.4\%; 


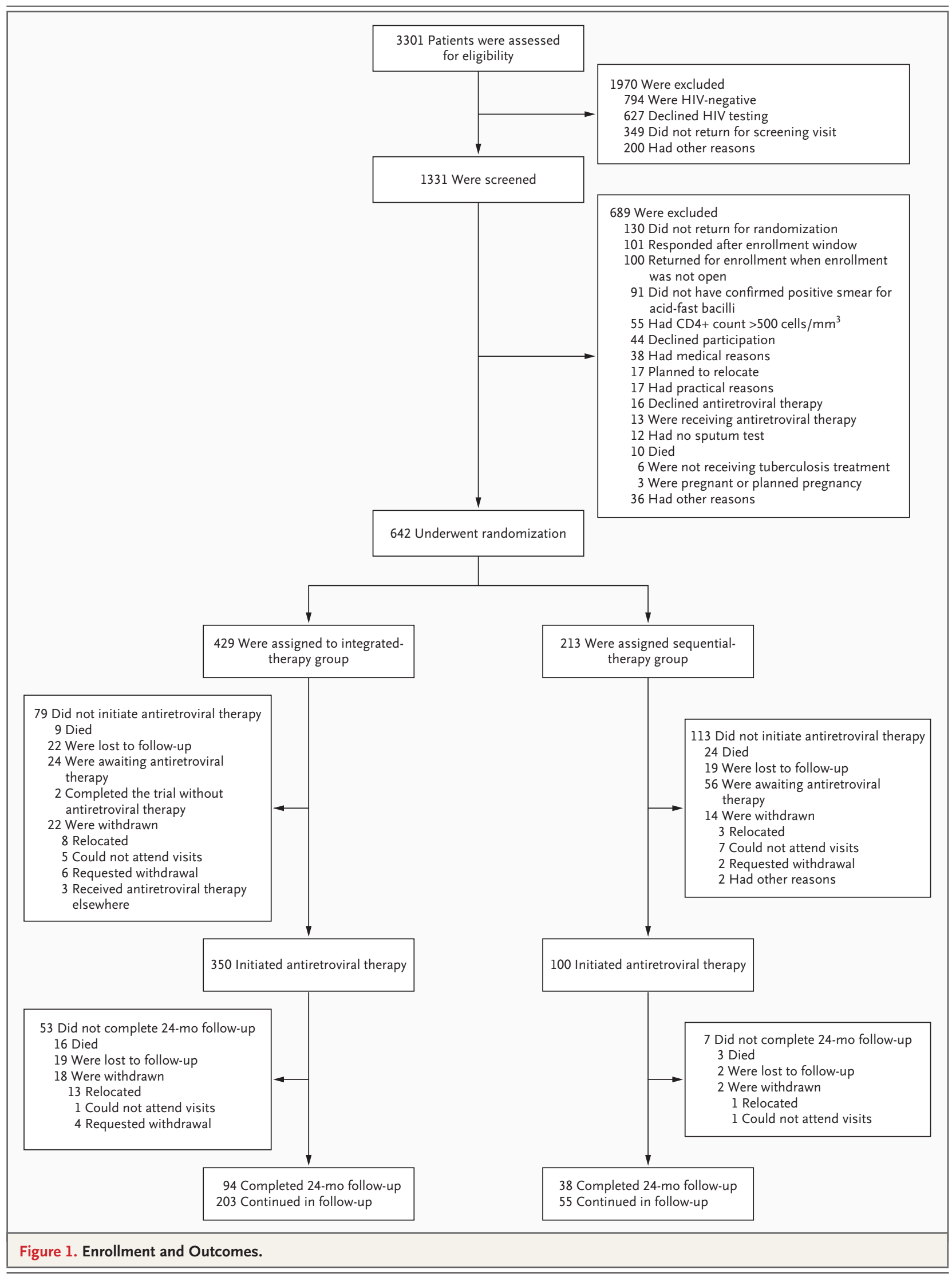




\begin{tabular}{|c|c|c|c|}
\hline Variable & $\begin{array}{l}\text { Integrated Therapy } \\
\qquad(N=429)\end{array}$ & $\begin{array}{l}\text { Sequential Therapy } \\
(N=213)\end{array}$ & P Value \\
\hline Age $-y r$ & & & 0.48 \\
\hline Mean & $34.4 \pm 8.38$ & $33.9 \pm 8.18$ & \\
\hline Range & $19-72$ & $19-60$ & \\
\hline Male sex - \% & 48.7 & 52.1 & 0.45 \\
\hline Educational level — no./total no. (\%) & & & 0.03 \\
\hline Primary school or less & $92 / 427(21.5)$ & $48(22.5)$ & \\
\hline Some secondary school & $205 / 427(48.0)$ & $80(37.6)$ & \\
\hline Completed secondary school & $130 / 427(30.4)$ & $85(39.9)$ & \\
\hline Employed — no./total no. (\%) & $251 / 428(58.6)$ & $116(54.5)$ & 0.35 \\
\hline History of tuberculosis — no. (\%) & $144(33.6)$ & $64(30.0)$ & 0.42 \\
\hline Karnofsky score - no./total no. (\%) & & & 0.44 \\
\hline 90 or 100 & $251 / 425(59.1)$ & $132 / 209(63.2)$ & \\
\hline 70 or 80 & $165 / 425(38.8)$ & $75 / 209$ (35.9) & \\
\hline$<70$ & $9 / 425(2.1)$ & $2 / 209(1.0)$ & \\
\hline Median CD4+ count (interquartile range) - cells $/ \mathrm{mm}^{3} \uparrow$ & $150(77-254)$ & $140(69-247)$ & 0.32 \\
\hline Median log viral load (interquartile range) - copies $/ \mathrm{ml}$ & $5.2(4.5-5.6)$ & $5.2(4.7-5.6)$ & 0.22 \\
\hline WHO stage 4 HIV infection - no. (\%)』 & $21(4.9)$ & $10(4.7)$ & 1.00 \\
\hline Presence of extrapulmonary tuberculosis - no. (\%) & $24(5.6)$ & $10(4.7)$ & 0.71 \\
\hline $\begin{array}{l}\text { Median no. of days of tuberculosis therapy at randomization } \\
\text { (interquartile range) }\end{array}$ & $9(1-14)$ & $9(7-16)$ & 0.15 \\
\hline \multicolumn{4}{|c|}{$\begin{array}{l}\text { Plus-minus values are means } \pm S D \text {. } \\
\text { Patients underwent randomization on the basis of the CD4+ count at screening (criterion for study enrollment, }<500 \\
\text { cells per cubic millimeter). However, for } 16 \text { patients, the CD4+ count at enrollment was more than } 500 \text { cells per cubic } \\
\text { millimeter. } \\
\text { The viral load at baseline was measured in } 397 \text { patients in the integrated-therapy group and in } 201 \text { patients in the se- } \\
\text { quential-therapy group. } \\
\text { The remainder of patients had stage } 3 \text { infection, according to criteria of the World Health Organization (WHO). }\end{array}$} \\
\hline
\end{tabular}

95\% CI, 9.5 to 15.9$)$ in the integrated-therapy group and in 8 of 213 patients (3.8\%; 95\% CI, 1.8 to 7.5$)$ in the sequential-therapy group $(\mathrm{P}<0.001)$. Six patients required the use of corticosteroids (five in the integrated-therapy group and one in the sequential-therapy group). No changes in the antiretroviral regimen were needed because of immune-reconstitution events. None of the deaths were determined to be related to the immune reconstitution inflammatory syndrome. Among grade 3 or 4 adverse events that were not regarded as immune reconstitution, 140 occurred in the integrated-therapy group (30 per 100 person-years) and 71 in the sequential-therapy group (32 per 100 person-years) $(P=0.69)$ (see the table in the Supplementary Appendix, available with the full text of this article at NEJM.org).

\section{I SCUSSION}

This trial showed that the initiation of antiretroviral therapy during tuberculosis therapy in patients with confirmed tuberculosis and HIV coinfection reduced mortality by 56\% (95\% CI, 21 to 75). The death rate rose from 5.4 per 100 personyears to 12.1 per 100 person-years when initiation of antiretroviral therapy was delayed until the completion of tuberculosis therapy. The interval between the completion of tuberculosis therapy and the initiation of antiretroviral therapy is important; a considerable number of deaths in the sequential-therapy group occurred during this time (Fig. 2). Once antiretroviral therapy was initiated, however, it was associated with similarly high levels of viral suppression in the two study 


\begin{tabular}{|c|c|c|c|c|c|c|c|c|c|c|}
\hline \multirow[t]{2}{*}{ CD4+ Count } & \multicolumn{4}{|c|}{ Integrated Therapy } & \multicolumn{4}{|c|}{ Sequential Therapy } & \multirow[t]{2}{*}{$\begin{array}{c}\text { Hazard Ratio } \\
(95 \% \mathrm{Cl}) *\end{array}$} & \multirow[t]{2}{*}{$\begin{array}{c}\mathrm{P} \\
\text { Value }\end{array}$} \\
\hline & $\begin{array}{c}\text { No. of } \\
\text { Patients }\end{array}$ & $\begin{array}{l}\text { No. of } \\
\text { Person- } \\
\text { Yr }\end{array}$ & $\begin{array}{l}\text { No. of } \\
\text { Deaths }\end{array}$ & $\begin{array}{l}\text { Death Rate/ } \\
100 \text { Person-Yr } \\
(95 \% \mathrm{Cl})\end{array}$ & $\begin{array}{l}\text { No. of } \\
\text { Patients }\end{array}$ & $\begin{array}{c}\text { No. of } \\
\text { Person- } \\
\text { Yr }\end{array}$ & $\begin{array}{l}\text { No. of } \\
\text { Deaths }\end{array}$ & $\begin{array}{l}\text { Death Rate/ } \\
100 \text { Person-Yr } \\
(95 \% \mathrm{Cl})\end{array}$ & & \\
\hline All patients & 429 & 467 & 25 & $5.4(3.5-7.9)$ & 213 & 223 & 27 & $12.1(8.0-17.7)$ & $0.44(0.25-0.79)$ & 0.003 \\
\hline$\leq 200$ cells $/ \mathrm{mm}^{3}$ & 273 & 281 & 23 & $8.2(5.2-12.3)$ & 138 & 137 & 21 & $15.3(9.6-23.5)$ & $0.54(0.30-0.98)$ & 0.04 \\
\hline$>200$ cells $/ \mathrm{mm}^{3}$ & 156 & 186 & 2 & $1.1(0.1-3.9)$ & 75 & 86 & 6 & $7.0(2.6-15.3)$ & $0.16(0.03-0.79)$ & 0.02 \\
\hline
\end{tabular}

* Hazard ratios are for the integrated-therapy group, as compared with the sequential-therapy group.

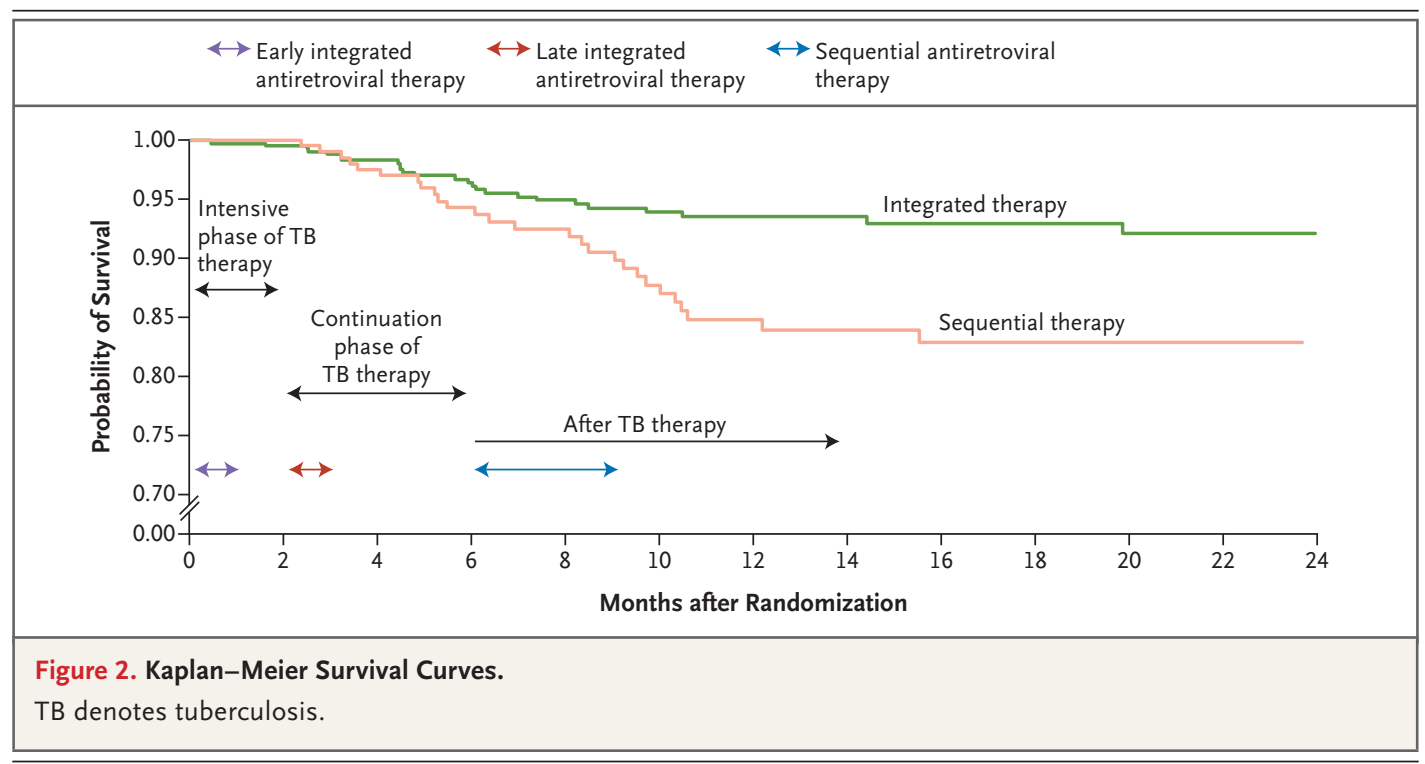

groups, findings that are similar to those observed in other HIV treatment programs in South Africa. ${ }^{17}$

Mortality among patients with HIV and tuberculosis coinfection is known to be high despite the use of effective tuberculosis therapy. ${ }^{5}$ Observational studies have indicated that the initiation of antiretroviral therapy during tuberculosis therapy improves treatment outcomes in such patients. A meta-analysis of studies involving 6934 patients at five hospitals in Madrid showed a significant improvement in survival (63\% increase) among patients who began antiretroviral therapy while they were receiving tuberculosis therapy.18 In Thailand, an analysis of 1003 patients showed an increase by a factor of 20 in the rate of death among patients who did not receive simultaneous antiretroviral and tuberculosis therapies, as compared with those who did receive the two therapies. ${ }^{19}$ A Thai review of studies involving
626 patients showed a hazard ratio for death of 0.17 for patients who started antiretroviral therapy during tuberculosis treatment, as compared with patients who did not receive antiretroviral therapy. ${ }^{20}$ Although the selection of patients for integrated treatment by clinicians may have led to bias in these studies, the trials show a consistent association between antiretroviral therapy and survival in coinfected patients. The randomized design of our trial validates and extends the findings from these retrospective observational data.

Among patients with $\mathrm{CD} 4+$ counts of less than 200 cells per cubic millimeter, the rate of death was $46 \%$ lower in the integrated-therapy group than in the sequential-therapy group $(\mathrm{P}=0.04)$. Although the number of deaths was small in the subgroup of patients who had CD4+ counts between 200 and 500 cells per cubic millimeter, there was a trend toward lower mortality in the 


\begin{tabular}{|c|c|c|c|c|c|}
\hline \multirow[t]{2}{*}{ Outcome } & \multicolumn{2}{|c|}{ Integrated Therapy $(\mathrm{N}=343)$} & \multicolumn{2}{|c|}{ Sequential Therapy $(N=171)$} & \multirow[t]{2}{*}{ P Value } \\
\hline & $\begin{array}{l}\text { Repeated Therapy } \\
\text { of Tuberculosis } \\
(\mathrm{N}=116)\end{array}$ & $\begin{array}{l}\text { First Episode of } \\
\text { Tuberculosis } \\
(\mathrm{N}=227)\end{array}$ & $\begin{array}{l}\text { Repeated Therapy } \\
\text { of Tuberculosis } \\
(\mathrm{N}=58)\end{array}$ & $\begin{array}{l}\text { First Episode of } \\
\text { Tuberculosis } \\
(\mathrm{N}=113)\end{array}$ & \\
\hline & \multicolumn{4}{|c|}{ number (percent) } & \\
\hline Tuberculosis cure† & $67(57.8)$ & $131(57.7)$ & $31(53.4)$ & $67(59.3)$ & 1.00 \\
\hline Successful completion $\nleftarrow$ & $16(13.8)$ & $42(18.5)$ & $5(8.6)$ & $16(14.2)$ & 0.20 \\
\hline Therapy success (cure plus successful completion) & $83(71.6)$ & $173(76.2)$ & $36(62.1)$ & $83(73.5)$ & 0.07 \\
\hline Died before completion of therapy & $7(6.0)$ & $12(5.3)$ & $6(10.3)$ & $9(8.0)$ & 0.19 \\
\hline Therapy interruption & $2(1.7)$ & $3(1.3)$ & $3(5.2)$ & $7(6.2)$ & 0.01 \\
\hline Therapy failure $\mathbb{Z}$ & 0 & 0 & 0 & $1(0.9)$ & 0.33 \\
\hline Loss to follow-up & $13(11.2)$ & $13(5.7)$ & $6(10.3)$ & $6(5.3)$ & 1.00 \\
\hline $\begin{array}{l}\text { Therapy outcome unknown because of transfer } \\
\text { to another clinic }\end{array}$ & $1(0.9)$ & $5(2.2)$ & $2(3.4)$ & $1(0.9)$ & 1.00 \\
\hline Other outcome & $1(0.9)$ & $1(0.4)$ & 0 & 0 & \\
\hline $\begin{array}{l}\text { Outcome pending (still receiving therapy at time } \\
\text { of analysis) }\end{array}$ & $9(7.8)$ & $20(8.8)$ & $5(8.6)$ & $6(5.3)$ & 0.49 \\
\hline \multicolumn{6}{|c|}{$\begin{array}{l}* \text { Only patients who were enrolled in the study at least } 7 \text { months before the date of the analysis are included. Percentages may not total } 100 \% \\
\text { because of rounding. } \\
\text { Tuberculosis cure was defined as a sputum smear that was negative for acid-fast bacilli close to the time of therapy completion. } \\
\text { T Successful completion of therapy was defined as the use of more than } 85 \% \text { of the prescribed medication. } \\
\mathbb{\int} \text { Therapy failure was defined as the presence of a positive smear or culture for Mycobacterium tuberculosis obtained at least } 5 \text { months after the } \\
\text { initiation of tuberculosis therapy. }\end{array}$} \\
\hline
\end{tabular}

integrated-therapy group. This finding has implications for treatment guidelines and policies. Current WHO guidelines for the treatment of patients with HIV and tuberculosis coinfection recommend the deferment of antiretroviral therapy until the completion of tuberculosis therapy in patients with WHO stage $3 \mathrm{HIV}$ infection and CD4+ counts of more than 200 cells per cubic millimeter. ${ }^{3,10}$ Our findings suggest that this guideline should be expanded to include cotreatment of HIV infection and tuberculosis in patients with CD4+ counts of less than 500 cells per cubic millimeter.

There is increasing evidence that even among patients with HIV infection who do not have tuberculosis, earlier initiation of antiretroviral therapy is associated with improved outcomes. ${ }^{21-23}$ In a study involving 8362 asymptomatic patients with HIV infection in the United States and Canada, ${ }^{22}$ mortality was $69 \%$ lower among patients in whom antiretroviral therapy was initiated when the CD4+ count was between 350 and 500 cells per cubic millimeter than in those in whom such therapy was deferred until the CD4+ count was less than 350 cells per cubic millimeter. Similarly, data from 18 prospective cohort studies have shown that deferring antiretroviral therapy was associated with higher rates of the acquired immunodeficiency syndrome (AIDS) and death than starting therapy when the CD4+ count was more than 350 cells per cubic millimeter. ${ }^{23}$

However, there are major concerns regarding the early initiation of antiretroviral therapy during tuberculosis treatment, including the increased risk of the immune reconstitution inflammatory syndrome, additive toxic effects, and the potential adverse effect on outcomes of tuberculosis therapy. We found similar rates of grade 3 and 4 adverse events in the two study groups and similar outcomes of tuberculosis therapy. Since many of the deaths occurred after the completion of tuberculosis therapy, the providers of such therapy were unaware of the benefits of cotherapy of tuberculosis and HIV infection. Although the incidence of immune-reconstitution events was significantly higher in the integrated-therapy group, this finding was not unexpected, since such events have been associated with the early initiation of antiretroviral therapy in patients with tuberculosis. ${ }^{24,25}$ The incidence of such events in the integrated-therapy group was similar to that observed in studies of other cohorts 


\begin{tabular}{|c|c|c|c|}
\hline Outcome & Integrated Therapy & Sequential Therapy & P Value \\
\hline \multicolumn{4}{|l|}{ Viral load $<400$ copies $/ \mathrm{ml}$} \\
\hline At 12 mo after randomization & & & 0.006 \\
\hline No./total no. & $199 / 221$ & $70 / 90$ & \\
\hline Percent $(95 \% \mathrm{CI})$ & $90.0(85.1-93.5)$ & $77.8(67.6-85.6)$ & \\
\hline At 6 mo after initiation of antiretroviral therapy & & & 0.40 \\
\hline No./total no. & $174 / 191$ & $39 / 45$ & \\
\hline Percent $(95 \% \mathrm{Cl})$ & $91.1(85.9-94.6)$ & $86.7(72.5-94.5)$ & \\
\hline \multicolumn{4}{|l|}{ Mean increase in CD4+ count from baseline } \\
\hline At 12 mo after randomization & & & 0.004 \\
\hline No. of patients & 207 & 84 & \\
\hline No. of cells $/ \mathrm{mm}^{3}(95 \% \mathrm{Cl})$ & $148.7(130.5-166.9)$ & $100.7(77.5-124.0)$ & \\
\hline At 6 mo after initiation of antiretroviral therapy & & & 0.71 \\
\hline No. of patients & 187 & 41 & \\
\hline No. of cells $/ \mathrm{mm}^{3}(95 \% \mathrm{Cl})$ & $124.2(105.4-143.1)$ & 116.3 (88.0 to 144.6$)$ & \\
\hline
\end{tabular}

in developing countries, ${ }^{24,26}$ including a retrospective analysis of hospitalized Thai patients receiving both antiretroviral and tuberculosis therapies, which showed that 21 of 167 patients (12.6\%) had an immune-reconstitution event. ${ }^{26}$ However, none of the deaths in our trial, in which data regarding the cause of death were available, were considered attributable to the immune reconstitution inflammatory syndrome. It is reassuring that recent studies of tuberculosis-associated immune reconstitution inflammatory syndrome indicate that this complication is rarely fatal and that severe episodes can be successfully managed with corticosteroids. ${ }^{27}$ Thus, the concern about increasing the likelihood of such episodes must be tempered by the survival benefit shown in our study. Nevertheless, the paradoxical deterioration in the clinical status is sufficiently common to warrant close clinical monitoring in the first few months after the initiation of antiretroviral therapy in patients coinfected with tuberculosis.

We acknowledge several limitations of our study. The use of death from any cause as the primary end point might underestimate the potential effect of integrated HIV-tuberculosis treatment on the rates of death specifically from tuberculosis or HIV infection. Since we were not able to obtain reliable information on the causes of all deaths in the trial, we were not able to estimate the effect on the rate of deaths that were related only to tuberculosis or HIV infec- tion. Since our trial included only patients who had a positive sputum smear for acid-fast bacilli and whose disease was diagnosed and treated in an outpatient tuberculosis clinic, the results may not be directly generalizable to all forms and severity levels of tuberculosis. Since a retrospective analysis of 549 patients with AIDS and extrapulmonary tuberculosis showed that the introduction of highly active antiretroviral therapy significantly improved survival, ${ }^{28}$ the early initiation of antiretroviral therapy may have similar benefits in patients with extrapulmonary tuberculosis. Although we have no reason to believe that our findings do not apply to sputum-smearnegative tuberculosis, our findings require empirical confirmation in this group. It should be noted that the judgment of study and nonstudy care providers took precedence over protocoldefined timing of the initiation of antiretroviral therapy, which led to early initiation of such therapy in some patients in the sequential-therapy group and delayed initiation in some patients in the integrated-therapy group. Another limitation was the delay in the initiation of antiretroviral therapy after the completion of tuberculosis therapy in the sequential-therapy group because of clinical issues (e.g., elevated levels of liver enzymes) or missed visits. Furthermore, the question of when antiretroviral therapy should be initiated during tuberculosis therapy awaits completion of the study.

In summary, our findings provide compelling 
evidence of the benefit of initiating antiretroviral therapy during tuberculosis therapy in patients with HIV coinfection. The findings also support recommendations by the WHO and others for the integration of tuberculosis and HIV care.

Supported by the U.S. President's Emergency Plan for AIDS Relief for the care of patients, the Global Fund to fight AIDS, Tuberculosis and Malaria for drugs used in the trial, and the Comprehensive International Program of Research on AIDS for the research infrastructure (including data management and laboratory and pharmacy facilities) to conduct the trial.

An overview of the results was presented at the 16th Conference on Retroviruses and Opportunistic Infections, Montreal, February 9, 2009.

Dr. S. Abdool Karim reports being listed as a coinventor on two patents (2000/3437 and PCT/IB02/04550) that are part of the development of clade C HIV vaccines; and Mr. Gray, receiving lecture fees from AstraZeneca, Aspen Pharmacare, and Fresenius Kabi. No other potential conflict of interest relevant to this article was reported.

We thank the patients for their participation in this study; Professor Willem Sturm of the Nelson R. Mandela School of Medicine for the confirmatory tuberculosis testing; Dr. Surie Chinnapa and Sr. Jeanne Liebertrau of the Prince Cyril Zulu Communicable Disease Centre; Drs. Gray Handley, Ed Tramont, Rod Hoff, Sandi Lehrman, and Richard Hafner of the Division of AIDS at the National Institutes of Health; Drs. Gavin Churchyard, Douglas Taylor, and Mark Weaver for serving on the data and safety monitoring committee; Ms. Anushka Naidoo for serving as the on-site study pharmacist; members of the Community Advisory Board; Ms. Nomapando Barnabas of the CAPRISA Community Programme; Ms. Natasha Samsunder and Mr. Keith Coetzee for laboratory analysis; Ms. Nonhlanhla Yende for statistical support; Ms. Irene van Middelkoop for data management; and all the other members of the study team.

\section{REFERENCES}

1. 2008 Report on the global AIDS epidemic: update. Geneva: Joint United Nations Programme on HIV/AIDS, 2008. (Accessed January 21, 2010, at http://www .unaids.org/en/KnowledgeCentre/HIVData/ GlobalReport/2008/2008_Global_report .asp.)

2. Global tuberculosis control: surveillance, planning, financing. Geneva: World Health Organization, 2008.

3. Abdool Karim SS. Durban 2000 to Toronto 2006: the evolving challenges in implementing AIDS treatment in Africa. AIDS 2006;20:N7-N9.

4. Churchyard GJ, Kleinschmidt I, Corbett EL, Mulder D, Smit J, de Kock KM. Factors associated with an increased casefatality rate in HIV-infected and noninfected South African gold miners with pulmonary tuberculosis. Int J Tuberc Lung Dis 2000;4:705-12.

5. Mukadi YD, Maher D, Harries A. Tuberculosis case fatality rates in high HIV prevalence populations in sub-Saharan Africa. AIDS 2001;15:143-52.

6. Schluger NW. Issues in the treatment of active tuberculosis in human immunodeficiency virus-infected participants. Clin Infect Dis 1999;28:130-5.

7. District health barometer $2006 / 2007$. Durban, South Africa: Health Systems Trust. (Accessed January 21, 2010, at http://www.hst.org.za/publications/717.)

8. Global tuberculosis control: epidemiology, strategy, financing: WHO report 2009. Geneva: World Health Organization, 2009.

9. National antiretroviral treatment guidelines. Pretoria, South Africa: South African Department of Health, 2004.

10. Treatment of tuberculosis: guidelines for national programmes. 3rd ed. Geneva: World Health Organization, 2003.

11. Piscitelli SC, Gallicano KD. Interactions among drugs for HIV and opportunistic infections. N Engl J Med 2001;344: 984-96.
12. Fishman JE, Saraf-Lavi E, Narita M, Hollender ES, Ramsinghani R, Ashkin D. Pulmonary tuberculosis in AIDS participants: transient chest radiographic worsening after initiation of antiretroviral therapy. AJR Am J Roentgenol 2000;174 43-9.

13. Chien JW, Johnson JL. Paradoxical reactions in HIV and pulmonary TB. Chest 1998;114:933-6.

14. Girardi E, Palmieri F, Cingolani A, et al. Changing clinical presentation and survival in HIV-associated tuberculosis after highly active antiretroviral therapy. J Acquir Immune Defic Syndr 2001;26: 326-31.

15. Abdool Karim SS, Abdool Karim Q, Friedland G, Lalloo U, El Sadr WM. Implementing antiretroviral therapy in resourceconstrained settings: opportunities and challenges in integrating HIV and tuberculosis care. AIDS 2004;18:975-9.

16. The South African national tuberculosis control programme: practical guidelines 2004. Pretoria, South Africa: South African Department of Health, 2004.

17. Lawn SD, Myer L, Wood R. Efficacy of antiretroviral therapy in resource-poor settings: are outcomes comparable to those in the developed world? Clin Infect Dis 2005;41:1683-4.

18. Velasco M, Castilla V, Sanz J, et al. Effect of simultaneous use of highly active antiretroviral therapy on survival of HIV patients with tuberculosis. J Acquir Immune Defic Syndr 2009;50:148-52.

19. Manosuthi W, Chottanapand S, Thongyen S, Chaovavanich A, Sungkanuparph S. Survival rate and risk factors of mortality among HIV/tuberculosiscoinfected patients with and without antiretroviral therapy. J Acquir Immune Defic Syndr 2006;43:42-6.

20. Sanguanwongse N, Cain KP, Suriya P, et al. Antiretroviral therapy for HIV-infected tuberculosis patients saves lives but needs to be used more frequently in Thai- land. J Acquir Immune Defic Syndr 2008; 48:181-9.

21. Sungkanuparph S, Manosuthi W, Kiertiburanakul S, Vibhagool A. Initiation of antiretroviral therapy in advanced AIDS with active tuberculosis: clinical experiences from Thailand. J Infect 2006;52:18894.

22. Kitahata MM, Gange SJ, Abraham AG, et al. Effect of early versus deferred antiretroviral therapy for HIV on survival. N Engl J Med 2009;360:1815-26.

23. Sterne JA, May M, Costaglola D, et al. Timing of initiation of antiretroviral therapy in AIDS-free HIV-1-infected patients: a collaborative analysis of 18 HIV cohort studies. Lancet 2009;373:1352-63.

24. Burman W, Weis $\mathrm{S}$, Vernon A, et al. Frequency, severity and duration of immune reconstitution events in HIV-related tuberculosis. Int J Tuberc Lung Dis 2007; 11:1282-9.

25. Meintjes G, Rangaka MX, Maartens G, et al. Novel relationship between tuberculosis immune reconstitution inflammatory syndrome and antitubercular drug resistance. Clin Infect Dis 2009;48:667-76.

26. Manosuthi W, Kiertiburanakul S, Phoorisri T, Sungkanuparph S. Immune reconstitution inflammatory syndrome of tuberculosis among HIV-infected patients receiving antituberculous and antiretroviral therapy. J Infect 2006;53:357-63.

27. Meintjes G, Wilkinson R, Morroni C, et al. Randomized placebo-controlled trial of prednisone for the TB immune reconstitution inflammatory syndrome. Presented at the 16th Conference on Retroviruses and Opportunistic Infections, Montreal, February 8-11, 2009. abstract.

28. García de Olalla P, Martínez-González MA, Caylà JA, et al. Influence of highly active anti-retroviral therapy (HAART) on the natural history of extra-pulmonary tuberculosis in HIV patients. Int J Tuberc Lung Dis 2002;6:1051-7.

Copyright @ 2010 Massachusetts Medical Society. 